\title{
A Comparative Study on the Effects of Use Hemp Seed Oil Substitute to Soybean Oil in Growing Quail Diets
}

\author{
Gülşah Kanbur ${ }^{1, a}$, Rabia Göçmen ${ }^{1, b, *}$ \\ ${ }^{1}$ Department of Animal Science, Faculty of Agriculture, University of Selcuk, 42130 Selçuklu/Konya, Turkey \\ *Corresponding author
}

A R T I C L I N F O A B S T R A T

Research Article

This study was conducted to investigate the effects of hemp seed oil replaced soybean oil as an energy supply on growth performance parameters, carcass yield, liver weight, breast meat $\mathrm{pH}$, and meat color values in quails. A total of 100 one-day old quail chicks were reared in two treatment groups for 5 weeks. The experimental diets were formulated as to contain $4.4 \%$ crude

Received : 07/10/2020

Accepted : 16/12/2020 soybean(control) and hemp seed oils. According to the results of the present study, crude hemp seed oil replaced soybean oil in the diet was effective on finishing body weight, feed intake, feed conversion ratio, weight gain and carcass yield. All of these parameters were lower than the soybean oil (control) group. Liver weight, and breast meat color values $\left(L^{*}, a^{*}\right.$, and $\left.b^{*}\right)$ have shown similarities between experimental groups. The breast meat $\mathrm{pH}$ value decreased significantly in the

Keywords:

Hemp seed oil hemp seed oil treatment group compared to soybean oil group. Using hemp seed oil instead of

Performance soybean oil used in quail diets negatively affects performance parameters (except for feed

Quail conversion ratio).

Meat

$\mathrm{pH}$

gkanbur@selcuk.edu.tr

http://orcid.org/0000-0002-6254-2257

b_rabiaacar@selcuk.edu.tr

http://orcid.org/0000-0001-9816-7746

This work is licensed under Creative Commons Attribution 4.0 International License

\section{Introduction}

Modern poultry production has common practice to use fat and oil for raising the energy density in poultry diets (Khatun et al., 2018; Parmar et al., 2019). Oils, besides of being energy source have important structural and metabolic functions such as, isolation of the body against environmental temperature alterations, transportation and the absorption of fat-soluble vitamins and providing of linoleic acid which is essential for poultry (Şenköylü, 2001). Although many types of vegetable and animal sources oils and fat used in poultry diets, crude soybean oil is one of the most preferred in the commercial context. However, due to a shortage of common vegetable oil sources such as soybean oil (SO), finding alternative oil sources has become an urgent requirement for poultry nutrition (Yang et al., 2019). Hemp seed oil is a by-product produced from hemp seeds and Hemp (Cannabis sativa L.) is an annual herbaceous plant which has been grown agriculturally for many centuries for its fiber and oil (Oomah et al., 2002). Hemp seed contains a high amount of protein $(20-25 \%)$, carbohydrate $(20-30 \%)$, oil (25$35 \%)$ and insoluble fiber $(10-15 \%)$, and also it is a rich source of minerals (Deferne and Pate, 1996; Pate, 1999; Oomah et al., 2002). Hemp seed also contain antinutritional factors such as phytic acid, trypsin inhibitors, condensed tannins, cyanogenic glycosides, and saponins (Russo and Reggiani, 2013, 2015; Galasso et al., 2016). Hemp seed oil is a valuable by-product that can extract by solvent or by screw press as virgin from seeds and crude oil can purification by refining (Matthäus and Brühl, 2008), and it is seen functional edible oil due to balanced fatty acid and high tocopherol content. Hemp seed oil has high level unsaturated fatty acids and the predominant fatty acids are linoleic and linolenic acids and its saturated fatty acid content is low. Tocopherol content amount of hemp seed oil is between 77-80 mg for each 100 $\mathrm{g}$ (Matthäus and Brühl, 2008) and this amount may change depending on the year, location, or variety. Hemp seed oil also contains approximately $4 \%$ gamma-linolenic acid (GLA), a unique n-6 fatty acid that serves as an intermediate for the formation of anti-inflammatory eicosanoids, which may have similar anti-inflammatory and anti-proliferative properties as EPA and DHA (Fan and Chapkin, 1998; Leizer et al., 2000; Kapoor and Huang, 2006). In some countries (Russia) hemp seed oil takes place as an alternative fat source in the human diet (Callaway, 2004). However, hemp seed oil can contain trace amounts THC (tetrahydrocannabinols) and the other cannabinoids which are lipophilic antioxidants that have 
the therapeutic potential (Callaway, 2004). Moreover, due to high polyunsaturated fatty acid composition of hemp seed oil is very susceptible to oxidative deterioration during long time storage or preparing food by heat processing (Matthäus and Brühl, 2008). Despite nutritional potential, due to consideration regarding THC content and rancidity probabilities hemp seed oil is less preferred worldwide for human nutrition compared to the other oils. Currently, hemp seed and its meal have been subject to animal nutrition researches, partially in poultry nutrition and various reports can found on the effect of hemp on growth and laying performance in poultry (Khan et al., 2010; Ondrej et al., 2015; Raza et al., 2016) but, studies regarding the effect of hemp seed oil in poultry nutrition are quite limited. It is well known that the source and type of dietary fat and influences on carcass quality of poultry meat (Khatun et al., 2018). The favorable composition of hemp seed oil provides evidence that it may represent a potentially valuable feed ingredient for poultry (Jing et al., 2017). Therefore, this study was conducted to determine the effects of using hemp seed oil obtained by pressing method instead of soybean oil in the quail rations on growth performance, meat color, carcass yield, liver weight and meat $\mathrm{pH}$.

\section{Materials and Methods}

The animal experiment was conducted at the application farm facility of Selçuk University Agriculture Faculty. Animal experiment was carried out according to the local ethics committee directives of Selçuk University. A total number of 100 quail (Coturnix coturnix Japonica), 1-day old were randomly distiributed in to two groups of 50 quail and then subdivided in to 5 replicates. Each group was fed on the two experimental diet,1-Control(SO) diet with $4.4 \%$ soybean oil, 2-Hemp seed oil(HSO) diet with $4.4 \%$ hemp seed oil no supplemented soybean oil (Table 1). The Soybean-corn based experimental diets were formulated according to recommendation National Research Council (NRC, 1994). The quails were reared in $33 \times 40 \times 28 \mathrm{~cm}$ size cages and under the semi-controlled environment terms (ventilation controlling system) and every compartment of cages had a water nipple, manger, and heater. The lighting program was 23 - hours light - 1 hour dark and during the trial, feed, and water provided as ad-libitum. Trial period was 5 weeks. Hemp (Cannabis sativa) seeds were provided from a local supplier and seeds were pressed in a cold press machine (Karaerler Machine, NF 100 model, Ankara) at about $45-50^{\circ} \mathrm{C}$ and crude hemp seed oil was obtained. Crude soybean oil was provided from a commercial feed factory. The nutrient composition of experimental diets was shown in Table 1.

At the beginning of the study (at $1 \mathrm{~d}$ of age) and at day $7,14,21,28$ and 35 the quails and feed intake were weighed to $1 \mathrm{~g}$ accuracy using an electronic balance. Quails live weight (LW) (g) was recorded and body weight gains (BWG) were calculated in weekly periods. Feed conversion ratio (FCR) was calculated with feed intake/body weight gain (FI/BWG) formulation.

At the end of the study (on d 35 of age), 3 quails ( 2 male, 1 female) from each replicate were randomly selected, weighed and slaughtered. After dressing, the carcass weight was measured (g) and dressing percentage calculated. Liver weight was measured.

Breast meat color values $\left(L^{*}, a^{*}, b^{*}\right)$ of quails were determined by a Konica Minolta chroma meter CR-400 (Minolta Camera Co., Osaka, Japan). The L value indicates the brightness, thea value indicates the redness and the $b$ value indicates the yellowness.

Breast meat value of quails was determined by using portable $\mathrm{pH}$ meter(WTW 2A20-1012 Waterproof pHMeter) (Horwitz and Latimer, 2000).

Statistical analysis of data were using 2 sample t-test in Minitab(2000).

Table 1. Nutrient composition of experimental growth period diets

\begin{tabular}{l|cc}
\hline \multicolumn{1}{c|}{ Ingredients (\%) } & SO diet & HSO diet \\
\hline Corn & 47.93 & 47.93 \\
Soybean meal & 44.52 & 44.52 \\
Soybean oil & 4.40 & - \\
Hemp seed oil & - & 4.40 \\
Limestone & 1.20 & 1.20 \\
DCP & 1.00 & 1.00 \\
Salt & 0.30 & 0.30 \\
Vitamin mineral Premix ${ }^{\text {A }}$ & 0.25 & 0.25 \\
Lysine & 0.20 & 0.20 \\
Methionine & 0.20 & 0.20 \\
\hline Total Calculated nutrients & 100 \\
\hline \multicolumn{2}{c}{ Crude Protein (\%) } & 24.0 \\
Metabolizable energy (kcal/kg) & 2900 & 24.0 \\
Calcium (\%) & 0.80 & 2900 \\
Available phosphorus (\%) & 0.30 & 0.80 \\
DL-Methionine (\%) & 0.50 & 0.50 \\
Methionine + Cysteine (\%) & 0.83 & 0.83 \\
L-Lysine (\%) & 1.30 & 1.30 \\
\hline SO: Soybea
\end{tabular}

SO: Soybean oil, HSO: Hempseed oil, **: Analyzed value, A:Vitaminmineral premix (per kilogram of diet): Vitamin A 15000 IU; Vitamin D3 1500 IU; Vitamin K 5 mg; Vitamin B1 3 mg; Vitamin B2 6 mg; Vitamin B6 $5 \mathrm{mg}$; Vitamin B12 $0.03 \mathrm{mg}$; Niacin $30 \mathrm{mg}$; Biotin $0.1 \mathrm{mg}$; calcium D-pantotenat $12.0 \mathrm{mg}$; folic acid $1.0 \mathrm{mg}$; coline chloride $400 \mathrm{mg}$; Manganese $80 \mathrm{mg}$; Iron $35 \mathrm{mg}$; Zinc $50 \mathrm{mg}$; Copper $5.0 \mathrm{mg}$; Iodine $2 \mathrm{mg}$; Cobalt $0.04 \mathrm{mg}$.

\section{Results and Discussions}

The effects of hemp seed oil in diets on growth performance parameters of quails were given in Table 2. The use of hemp seed oil (HSO) instead of soybean oil in the quail diet significantly affected FBW(final body weight), FCR, FI and WG $(\mathrm{P}<0.05)$. Performance parameters of the HSO group were lower than the control group.

In the literature, there is almost no research on the addition of hemp oil to poultry diets. Current studies are mostly focused on hemp seed meal, hempseed cake and hemp seeds. Gakhar et al. (2012) reported that the inclusion of the hemp products hemp seed or hemp seed oil in the diets of laying hens up to a maximum level of 20 and $12 \%$, respectively, does not negative effect the performance. Ondrej et al. (2015) reported that with the addition of $15 \%$ hemp seed cake in the broiler diet, FBW and FCR significantly decreased compared control group. Vispute et al. (2019) demonstrated that supplemented level of $0.2 \%$ and $0.3 \%$ whole hemp seed to basal broiler ration affected 
negatively FI and BWG at first 21 days period, however, among 21 and 42 days were not observed a significant difference between treatments. Mahmoudi et al. (2015) reported that whole hemp seed addition to ration affected daily FI and BWG of broilers depending on the level and it has been demonstrated that in the lower level $(25 \mathrm{~g} / \mathrm{kg}$ feed $)$ of whole hemp seed decreased these parameters compared to higher levels (50-75 gr/kg feed). Bahari et al. (2014) have reported that added different levels of whole hemp seed to broiler diets were effect on feed conversion ratio and in treatment groups, the FI was decreased in 3rd, 4th, 5 th and 6th weeks compared control groups. Konca et al. (2014) have revealed that FI and FCR of broiler chickens were not affected by supplemental whole hemp seed in the rations however FBW significantly decreased at the group which has the highest hemp seed level. Adding different levels $\left(50 \mathrm{~g} / \mathrm{kg}^{-1}\right.$ and $\left.150 \mathrm{~g} / \mathrm{kg}^{-1}\right)$ of hempseed expellers to broiler rations has been negatively affects $\mathrm{LW}$ and $\mathrm{FCR}(\mathrm{P}<0.05)$. The best values were recorded in the control group. However, it has been reported to appears to affect the colour and odour of broiler chicken's meat which is positive for the consumers (Š́t'astník et al., 2019). Eriksson and Wall (2012) reported that supplemented of hempseed cake in organic broiler's diets did not affect production performance and mortality.

According to the results of this study performance parameters negative affected by hempseed oil which replaced soybean oil $(\mathrm{P}<0.05)$. Results of previous studies have indicated that supplemental level, varieties of hempseed, differences of by-products of hempseed, oil content of by-products, and effective components such as THC, cannabinoids, phenolics, and their levels may be considered influential on performance parameters in the growth period of poultry. Hemp oil, due to the lipophilic nature of THC, could be expected to contain more THC than the seed (Additives and Feed, 2011). In our study, if there were groups with all soybean oil and certain levels of additives in the ration, the amount of hemp seed oil that could be used without negative effects could be determined.

Table 2. The effects of hemp seed oil in diets on growth performance parameters of quails.

\begin{tabular}{l|cccc}
\hline \multicolumn{1}{c|}{ Diets } & FBW $(\mathrm{g})$ & BWG $(\mathrm{g})$ & FI $(\mathrm{g})$ & FCR \\
\hline Control (SO) & $173.06 \pm 2.4^{\mathrm{a}}$ & $164.50 \pm 2.3^{\mathrm{a}}$ & $479.5 \pm 11^{\mathrm{a}}$ & $2.92 \pm 0.09^{\mathrm{a}}$ \\
Hemp seed oil (HSO) & $164.47 \pm 2.3^{\mathrm{b}}$ & $155.93 \pm 2.4^{\mathrm{b}}$ & $395.2 \pm 21^{\mathrm{b}}$ & $2.53 \pm 0.12^{\mathrm{b}}$ \\
\hline
\end{tabular}

a, b: Means with different minuscule in the same column are significantly different at $\mathrm{P}<0.05$, (FBW: Finishing body weight, WG: Weight gain, FI: Feed intake, FCR: Feed conversion ratio, SO: Soybean oil HSO: Hempseed oil)

Table 3. The effects of hemp seed oil in diets on carcass yield, liver weight and breast meat pH of quails.

\begin{tabular}{l|ccc}
\hline \multicolumn{1}{c|}{ Diets } & CY $(\%)$ & LW $(\mathrm{g})$ & $\mathrm{pH}$ \\
\hline Control (SO) & $69.67 \pm 0.48^{\mathrm{a}}$ & $3.61 \pm 0.14$ & $5.77 \pm 0.02^{\mathrm{a}}$ \\
Hemp seed oil (HSO) & $67.92 \pm 0.29^{\mathrm{b}}$ & $3.30 \pm 0.01$ & $5.69 \pm 0.02^{\mathrm{b}}$ \\
\hline
\end{tabular}

a, b: Means with different minuscule in the same column are significantly different at $\mathrm{P}<0.05$, (CY: Carcass yield, LW: Liver weight, SO: Soybean oil HSO: Hempseed oil).

Table 4. The effects of hemp seed oil and soybean oil in diet on quail breast meat colour values.

\begin{tabular}{l|cccccc}
\hline \multirow{2}{*}{ Diets } & \multicolumn{3}{|c}{ Skinned } & \multicolumn{3}{c}{ Skinless } \\
\cline { 2 - 6 } & $L^{*}$ & $a^{*}$ & $b^{*}$ & $L^{*}$ & $a^{*}$ & $b^{*}$ \\
\hline Control (SO) & $59.64 \pm 1.30$ & $6.17 \pm 0.57$ & $5.96 \pm 0.76$ & $57.13 \pm 3.10$ & $5.61 \pm 0.42$ & $3.8 \pm 1.20$ \\
Hemp seed oil (HSO) & $59.56 \pm 0.93$ & $6.71 \pm 0.45$ & $6.16 \pm 0.29$ & $52.19 \pm 1.40$ & $6.64 \pm 0.99$ & $2.19 \pm 0.43$ \\
\hline
\end{tabular}

HSO: Hempseed oil, SO: Soybean oil

The effects of dietary oils in diets on carcass yield, liver weight and breast meat $\mathrm{pH}$ of quails were given Table 3 . Hempseed oil was decreased significantly in carcass yield and breast meat $\mathrm{pH}$ compared to soybean oil $(\mathrm{P}<0.05)$ however, liver weight were not affected by treatments.

The quality of a meat is shaped by a complex interaction between the genotype of the animal from which it is obtained and the environment (Bihan-Duval, 2004). As a result of the decrease in $\mathrm{pH}$, the meat becomes more moisture and tender (Savell et al., 2005). Using hemp oil instead of soybean oil in the diet has decreased the $\mathrm{pH}$ value and positively affected the meat quality. Meat $\mathrm{pH}$ value can be affected by amounts of antioxidants and some other compounds in the diet (Khan et al., 2015) and it is clear that the level of antioxidants and the other components can be effective on meat $\mathrm{pH}$ able to show alterations between oil and by-products of hempseed.

Carcass yield is significantly higher in the SO group compared to the HSO group $(\mathrm{P}<0.05)$. Liver weight was found higher in the soybean oil group but not significant statistically. Konca et al. (2014) noticed that whole hemp seed at the level of $0 \%$ (control group), 5\%, 10\% and $20 \%$ in the ration were significant on carcass and liver weights, and $10 \%$ hemp seed supplementation increased carcass weight but the highest liver weight was found in the control group. Khan et al. (2010) revealed that the hemp seed powder added to the feed at the level of $20 \%$ has a positive effect on the carcass quality of broiler chicks. Outcomes of various studies regard the effect of hemp seed oil or byproducts on carcass and liver weights have shown that many factors such as poultry species, supplement level, and potential effective components are efficient on the results. Ondrej et al. (2015) reported that 5\% and 15\% hemp seed cake supplemented rations were not significantly effective in terms of broiler carcass yield.

The effect of dietary oils on quail breast meat color values $\left(L^{*}, a^{*}, b^{*}\right)$ in Table 4 was shown. Color values of skinless and skinned breast meat were not affected significantly by the hemp seed oil supplement. 
Despite no significant difference between groups in terms of color value, $L^{*}, a^{*}$ and $b^{*}$ values of skinned and skinless breast meat were differential as estimated. In this study, hemp seed oil affected the $\mathrm{pH}$ value but not changed the color values of breast meat. Despite muscle $\mathrm{pH}$ and meat color have consistently been reported to be highly correlated however similarly to this study, several scientists have not found consistent relationships between color and $\mathrm{pH}$ in "normal" conditions and it has been reported that meat $\mathrm{pH}$ and color strongly related under the extreme conditions (Fletcher, 2002). Reports regarding the effects of hemp seed oil on poultry meat color have not found but a study that has investigated the effect of two levels of hemp seed expeller (50 and $150 \mathrm{gr} / \mathrm{kg}$ feed) on broiler meat color values and reported that $L^{*}$ value not changed by treatments but $\% 15$ hemp seed cake in the diet affected $a^{*}$ and $b^{*}$ values significantly and caused more intense color (Št’astník et al., 2019). Aminzade et al. (2012) have notified that the effectiveness of oxidative processes affected the meat discoloration. The present study has revealed that supplemental hemp seed oil replaced soybean oil was not changed the color values of meat samples and any oxidative case has not been able to change of meat color.

\section{Conclusions}

Results of this study demonstrated that hemp seed oil replaced soybean oil in the diet was effective on finishing body weight, feed intake, feed conversion ratio, weight gain and carcass yield $(\mathrm{P}<0.05)$. All of these parameters were lower than the soybean oil group. Liver weight, and breast meat color values $\left(L^{*}, a^{*}\right.$, and $\left.b^{*}\right)$ have shown similarities between experimental groups. The breast meat $\mathrm{pH}$ value decreased significantly in the hemp seed oil treatment group $(\mathrm{P}<0.05)$. Using hemp seed oil instead of soybean oil used in quail rations negatively affects performance parameters (except feed conversion ratio). Hemp seed oil is a product that has the potential to have very important effects in poultry feeding. Studies are needed to determine the levels of hemp seed oil that can be used in poultry diets without any adverse effects.

\section{References}

Additives EPo, PoSui A. Feed. 2011. Scientific Opinion on the safety of hemp (Cannabis genus) for use as animal feed. EFSA Journal 9(3): 2011.

Aminzade B, Karami B, Lotfi E. 2012. Meat quality characteristics in Japanese quails fed with Mentha piperita plant. Animal Biology \& Animal Husbandry 4(1): 20-24.

Bahari M, Bahari M, Khorshidi KJ, Abdullahpour R, Gharahveysi S. 2014. Effect of Using Medicinal Cannabis Seed (Nigella sativa) in Diets on Performance and Parameters of Broiler Chickens ROSS 308. Advances in Environmental Biology 8(13): 931-935.

Bihan-Duval EL. 2004. Genetic variability within and between breeds of poultry technological meat quality. World's Poultry Science Journal 60(3): 331-340.

Callaway J. 2004. Hempseed as a nutritional resource: An overview. Euphytica 140(1-2): 65-72.

Deferne J.-L, Pate DW. 1996. Hemp seed oil: A source of valuable essential fatty acids. Journal of the International Hemp Association 3(1): 4-7.
Eriksson M, Wall H. 2012. Hemp seed cake in organic broiler diets. Animal feed science and technology 171(2-4): 205-213.

Fan YY, Chapkin RS. 1998. Importance of dietary $\gamma$-linolenic acid in human health and nutrition. The Journal of nutrition 128(9): 1411-1414.

Fletcher D. 2002. Poultry meat quality. World's Poultry Science Journal 58(2): 131-145.

Gakhar N, Goldberg E, Jing M, Gibson R, House J. 2012. Effect of feeding hemp seed and hemp seed oil on laying hen performance and egg yolk fatty acid content: Evidence of their safety and efficacy for laying hen diets. Poultry Science 91(3): 701-711.

Galasso I, Russo R, Mapelli S, Ponzoni E, Brambilla IM, Battelli G, Reggiani R. 2016. Variability in seed traits in a collection of Cannabis sativa L. genotypes. Frontiers in Plant Science 7: 688.

Horwitz W, Latimer G. 2000. AOAC International: Gaithersburg. MD, USA

Jing M, Zhao S, House J. 2017. Performance and tissue fatty acid profile of broiler chickens and laying hens fed hemp oil and HempOmegaTM. Poultry science 96(6): 1809-1819.

Kapoor R, Huang YS. 2006. Gamma linolenic acid: an antiinflammatory omega- 6 fatty acid. Current pharmaceutical biotechnology 7(6): 531-534.

Khan A, Allen K, Wang X. 2015. Effect of Type I and Type II antioxidants on oxidative stability, microbial growth, $\mathrm{pH}$, and color in raw poultry meat. Food and Nutrition Sciences 6(16): 1541.

Khan RU, Durrani F, Chand N, Anwar H. 2010. Influence of feed supplementation with Cannabis sativa on quality of broilers carcass. Pakistan Veterinary Journal 30(1): 34-38.

Khatun J, Loh T, Akit H, Foo H, Mohamad R. 2018. Influence of different sources of oil on performance, meat quality, gut morphology, ileal digestibility and serum lipid profile in broilers. Journal of Applied Animal Research 46(1): 479-485.

Konca Y, Cimen B, Yalcin H, Kaliber M, Beyzi SB. 2014. Effect of hempseed (Cannabis sativa sp.) inclusion to the diet on performance, carcass and antioxidative activity in Japanese quail (Coturnix coturnix japonica). Korean journal for food science of animal resources 34(2): 141.

Leizer C, Ribnicky D, Poulev A, Dushenkov S, Raskin I. 2000. The composition of hemp seed oil and its potential as an important source of nutrition. Journal of Nutraceuticals, functional \& medical foods 2(4): 35-53.

Mahmoudi M, Farhoomand P, Nourmohammadi R. 2015. Effects of different levels of hemp seed (Cannabis sativa L.) and dextran oligosaccharide on growth performance and antibody titer response of broiler chickens. Italian Journal of Animal Science 14(1): 3473.

Matthäus B, Brühl L. 2008. Virgin hemp seed oil: An interesting niche product. European Journal of Lipid Science and Technology 110(7): 655-661.

NRC. 1994. Nutrient requirements of poultry: 1994. National Academies Press.

Ondrej S, Hana S, Vaclav T, Tomas V, Leos P, Eva M. 2015. The effect of hempseed cakes on broiler chickens peroformance parameters. Mendelnet 1(1): 157-160.

Oomah BD, Busson M, Godfrey DV, Drover JC. 2002. Characteristics of hemp (Cannabis sativa L.) seed oil. Food chemistry 76(1): 33-43.

Parmar AB, Patel VR, Usadadia SV, Chaudhary LM, Londhe DRPAS. 2019. Influence of Dietary Inclusion of Oil and Quercetin Supplementation on Carcass Characters and Meat Quality Attributes of Broiler Chickens. 8(9): 68-74.

Pate DW. 1999. Hemp seed: a valuable food source. Advances in hemp research: 243-255.

Raza T, Chand N, Khan RU, Shahid MS, Abudabos AM. 2016. Improving the fatty acid profile in egg yolk through the use of hempseed (Cannabis sativa), ginger (Zingiber officinale), and turmeric (Curcuma longa) in the diet of Hy-Line White Leghorns. Archives Animal Breeding 59(2): 183-190. 
Russo R, Reggiani R. 2013. Variability in antinutritional compounds in hempseed meal of Italian and French varieties. Plant 1(2): 25-29.

Russo R, Reggiani R. 2015. Evaluation of protein concentration, amino acid profile and antinutritional compounds in hempseed meal from dioecious and monoecious varieties. American Journal of Plant Sciences 6(01): 14.

Savell J, Mueller S, Baird B. 2005. The chilling of carcasses. Meat Science 70(3): 449-459.

Št’astník O, Jůzl M, Karásek F, Fernandová D. Mrkvicová E, Pavlata L, Nedomová Š, Vyhnánek T, Trojan V, Doležal P. 2019. The effect of hempseed expellers on selected quality indicators of broiler chicken's meat. Acta Veterinaria Brno 88(1): 121-128.
Şenköylü N. 2001. Yemlik yağlar, Trakya Üniversitesi, Yemler ve Hayvan Besleme Anabilim Dalı, Tekirdağ

Vispute MM, Sharma D, Mandal AB, Rokade JJ, Tyagi PK, Yadav AS. 2019. Effect of dietary supplementation of hemp (Cannabis sativa) and dill seed (Anethum graveolens) on performance, serum biochemicals and gut health of broiler chickens. Journal of animal physiology and animal nutrition 103(2): 525-533.

Yang A, Qi M, Wang X, Wang S, Sun L, Qi D, Zhu L, Duan Y, Gao X, Ali Rajput S. 2019. Refined cottonseed oil as a replacement for soybean oil in broiler diet. Food science \& nutrition 7(3): 1027-1034. 